\title{
2, 4-Dichloro-6-nitrophenol, a photonitration product of 2, 4- dichlorophenol, caused anti-androgenic potency in Chinese rare minnows (Gobiocypris rarus)
}

\author{
Rui Chen ${ }^{\text {a, d }}$, Cao Liu ${ }^{b}$, Lilai Yuan ${ }^{\text {a, d }}$, Jinmiao Zha ${ }^{\text {a, c, * }}$, Zijian Wang ${ }^{\text {c, d }}$ \\ ${ }^{a}$ Key Laboratory of Drinking Water Science and Technology, Research Center for Eco-Environmental Sciences, Chinese Academy of Sciences, Beijing, 100085, \\ China \\ ${ }^{\mathrm{b}}$ Beijing Water Sciences and Technology Institute, Beijing, 100048, China \\ c Beijing Key Laboratory of Industrial Wastewater Treatment and Reuse, Research Center for Eco-Environmental Sciences, Chinese Academy of Sciences, \\ Beijing, 100085, China \\ d State Key Laboratory of Environmental Aquatic Chemistry, Research Center for Eco-Environmental Sciences, Chinese Academy of Sciences, Beijing, 100085, \\ China
}

\section{A R T I C L E I N F O}

\section{Article history:}

Received 7 April 2016

Received in revised form

3 June 2016

Accepted 7 June 2016

Available online 17 June 2016

\section{Keywords:}

Chinese rare minnows

2,4-Dichloro-6-nitrophenol

Environmental transformation products

Endocrine disruption

\begin{abstract}
A B S T R A C T
2,4-Dichloro-6-nitrophenol (DCNP) is an environmental transformation product of 2,4-dichlorophenol that has been identified as widespread in effluent wastewater, but little is known about its toxicity because this compound is not regulated. Therefore, to investigate the endocrine disruption potency of DCNP in Chinese rare minnows (Gobiocypris rarus), adult and juvenile fish were exposed to various concentrations of DCNP $(2,20$, and $200 \mu \mathrm{g} / \mathrm{L})$ for $28 \mathrm{~d}$. After $28 \mathrm{~d}$ exposure, the plasma vitellogenin (VTG) levels were reduced in females while increased in males and juvenile fish considerably, as compared with the control. These results suggested that DCNP affects the HPG-axis in a sex-dependent way. Testosterone $(\mathrm{T})$ levels in the plasma were significantly lower in adult and juvenile fish and were accompanied by an increased estradiol (E2)/T ratio. Histopathological observation revealed hypertrophy of the hepatocytes and nuclear pyknosis in the liver, the inhibition of spermatogenesis in the testes, and the degeneration of oocytes in the ovaries after DCNP exposure. The expression pattern of selected genes indicated that the nuclear receptor, steroidogenesis and gonadotropin regulation pathways were perturbed after DCNP exposure. Above all, our results demonstrated that DCNP clearly had anti-androgenic activity in both adult and juvenile fish and can therefore be considered as an endocrine-disrupting chemical.
\end{abstract}

๑) 2016 Elsevier Ltd. All rights reserved.

\section{Introduction}

2,4-Dichloro-6-nitrophenol (DCNP), a rarely produced and used chemical, is an environmental transformation product of 2,4-

Abbreviations: DCNP, 2,4-dichloro-6-nitrophenol; DCP, 2,4-dichlorophenol; VTG, vitellogenin; T, testosterone; E2, estradiol; ER, estrogen receptor; AR, androgen receptor; HSI, hepatosomatic index; GSI, gonadosomatic index; LH, luteinizing hormone; FSH, follicle stimulating hormone; StAR, steroidogenic acute regulatory protein; CYP, cytochrome P450; HSD, hydroxysteroid.

This paper has been recommended for acceptance by Harmon Sarah Michele.

* Corresponding author. State Key Laboratory of Environmental Aquatic Chemistry Research Center for Eco-Environmental Sciences, Shuangqing Rd 18, Haidian District, Beijing, 100085, China.

E-mail addresses: jmzha@rcees.ac.cn, jinmiaozha@gmail.com (J. Zha). dichlorophenol (DCP) (Calza et al., 2008; Vione et al., 2006). Previous studies have reported the photonitration of phenols by nitrite and nitrate ions that absorb sunlight and generate reactive species and then attack the aromatic ring (Maddigapu et al., 2010; Vione et al., 2007). This process is important for the transformation of phenols in surface waters and produces various nitrophenols, including DCNP (Mack and Bolton, 1999; Minero et al., 2007). In addition, the kinetics of DCNP formation depend on both substraterelated and ecosystem-related variables, especially the chemical composition of the water and sunlight penetration (Loiselle et al., 2009). DCNP formation is known to be associated with nitrate ions, which are present in water at concentrations ranging from 10 to $30 \mu \mathrm{M}$ (Calza et al., 2012; Dehairsl, 1991; Dzengel et al., 1999; Madronich and Flocke, 1998). DCP, a precursor of DCNP, is a key intermediate in the synthesis of chloride-based herbicides such as 
2,4-dichlorophenoxyacetic acid (2,4-D) and 2-(2,4dichlorophenoxy) propionic acid (2,4-DP) (Chiron et al., 2007; Crespín et al., 2001). Moreover, DCP is commonly found in water and soil environments and is typically used in agriculture and manufacturing (Palomo and Bhandari, 2005; Zhong et al., 2012). In China, DCP has been detected in 51.3\% of the surface water, and the maximum concentration was $19.96 \mu \mathrm{g} / \mathrm{L}$ (Gao et al., 2008). As an environmental by-product of the ubiquitous DCP, DCNP has been detected in the brackish lagoons of southern France in which its maximum level $(1.32 \mu \mathrm{g} / \mathrm{L})$ was comparable to that of the parent herbicide $(4.72 \mu \mathrm{g} / \mathrm{L})$ (Chiron et al., 2007).

Phenolic compounds are important chemical raw materials and were detected ubiquitously in surface water and wastewater (Czaplicka, 2004; Olaniran and Igbinosa, 2011). Attention to phenolic compounds is increasing due to high environmental concentrations and toxicity (MacAyeal, 1999), but consideration of the possible environmental significance of environmental transformation products of phenols in water is rare. In surface water, a variety of photomodification reactions of phenols lead to the formation of numerous intermediates (Dzengel et al., 1999; Machado and Boule, 1995) that are more toxic than the parent compound (Chiron et al., 2009; Schulze et al., 2010; Wang et al., 2009), such as DCNP (Chiron et al., 2006). Moreover, nitration can generate carcinogenic and mutagenic compounds (Machado and Boule, 1995; Suzuki et al., 1982). Therefore, as a product of nitration, DCNP has been shown to have genotoxic effects including gene mutation and chromosomal aberrations (Heng et al., 1996a, 1996b; Kroeger-Koepke et al., 1992). However, little data relating to the toxicity of DCNP is available (Tognazzi et al., 2012).

Many substituted phenols have been shown not only to be toxic but also to be endocrine disruptors (Gyllenhammar et al., 2012). Some substituted phenols are estrogen-mimicking substances that bind to estrogen receptors (ERs) and androgen receptors (ARs) and show estrogenic or anti-androgenic activity (Klinge, 2000). Moreover, Nishihara have reported that substituted phenols (e.g., BPA, 3,4- dichlorophenol, and pentachlorophenol) were potential agonists to the rat ER (Nishihara et al., 2000), but their anti-androgenic activity was measured using a recombinant yeast assay (Li et al., 2010). In addition, in vivo studies have indicated that substituted phenols can alter the expression of the steroid receptors associated with changes in the metabolism of xenobiotics and steroid hormones (Zhang et al., 2008). Therefore, potent estrogenic effects of substituted phenols (e.g., Nonylphenol and Tribromophenol) have been found in vitro (Bonefeld-Jorgensen et al., 2007) and in vivo (Deng et al., 2010; Duffy et al., 2014). However, the impact on the endocrine system is not the same as that of natural hormones because the estrogenic effects of substituted phenols are weak. Studies have demonstrated that the VTG and estradiol levels in male or juvenile fish exposed to substituted phenols, including nonylphenol, nitrophenol, and 2,4-dichlorophenol, were significantly increased but were significantly decreased in females ( $\mathrm{Li}$ et al., 2006b; Ma et al., 2012; Zha et al., 2007). These findings appear to contradict the estrogenic properties of substituted phenols; it seemed that substituted phenols are anti-estrogenic, not estrogenic, in females (Chikae et al., 2004; Lei et al., 2013). Although DCNP is a substituted phenol structurally similar to dichlorophenol and nitrophenol, the disruption of endocrine system by DCNP and its environmental risk to fish are not well documented.

Therefore in the present study, adult and juvenile Chinese rare minnows (Gobiocypris rarus) were exposed to an environmental concentration $(2 \mu \mathrm{g} / \mathrm{L})$ and two higher concentrations (20 and $200 \mu \mathrm{g} / \mathrm{L}$ ) of DCNP for $28 \mathrm{~d}$ to investigate the sub-chronic toxicity and the endocrine disrupting potency of DCNP. The rare minnow is an endemic fish species used as a model for environmental pollution screening and chemical toxicity assessment. The rare minnow possess several characteristics in ecotoxicology, including small size, ease of culture, short life cycle and prolific egg production (Liang et al., 2014; Yuan et al., 2013). To assess the endocrine disrupting effects of DCNP, growth, histopathological changes, hormone and VTG levels and the expression of HPG-axis related genes were determined and compared after exposure.

\section{Materials and methods}

\subsection{Chemicals}

DCNP (CAS no. 609-89-2; purity >98\%) was purchased from Sigma (Chemical Co., USA). A stock solution of DCNP was prepared by dilution in acetone (purity > 99.9\%; Sinopharm, China). All resultant exposure media contained $0.01 \%$ acetone.

\subsection{Test fish and culture conditions}

The brood stock of the rare minnows has been used for testing chemicals in our laboratory for more than 14 years. In the present study, rare minnows were kept in $16 \mathrm{~L}$ aquaria with a flow through system under $16 \mathrm{~h}$ light $/ 8 \mathrm{~h}$ dark photoperiod. Temperature and $\mathrm{pH}$ of water were $25 \pm 1{ }^{\circ} \mathrm{C}$ and $7.5 \pm 0.3$, respectively (Liang et al., 2014; Yuan et al., 2013). Fish were fed twice a day (0.1\% bodyweight, b.w.) with commercial food pellet (Trea, Germany) and newly hatched brine shrimp (Artemia nauplii).

\subsection{Experimental design}

Two experimental groups were set up. In the first group, healthy juvenile rare minnows with average bodyweights and lengths of $0.36 \pm 0.07 \mathrm{~g}$ and $28.6 \pm 1.4 \mathrm{~mm}$, respectively, were randomly divided into four groups of 30 fish. After acclimation for 7 days, the fish were exposed to various concentrations of $\operatorname{DCNP}(0,2,20$, and $200 \mu \mathrm{g} / \mathrm{L}$ ). Three replicates were done per treatment.

In the second group, healthy adult rare minnows, seven months old and the offspring from the same pair of brood stock, were randomly divided into eight groups of 30 fish (1:1). The bodyweights and lengths of the male fish were $0.67 \pm 0.16 \mathrm{~g}$ and $39.7 \pm 1.5 \mathrm{~mm}$. The bodyweights and lengths of the female fish were $0.81 \pm 0.10 \mathrm{~g}$ and $41.4 \pm 2.2 \mathrm{~mm}$, respectively. After acclimation for 7 days, the fish were exposed to various concentrations $(0$, 2, 20, and $200 \mu \mathrm{g} / \mathrm{L}$ ) of DCNP. Three replicates were done per treatment.

\subsection{Plasma E2, T and VTG measurement}

After exposure, 30 rare minnows in each aquarium were collected. Plasma was collected by centrifugation $(5000 \times \mathrm{g}$ for $10 \mathrm{~min}$ at $4{ }^{\circ} \mathrm{C}$ ) of whole blood, and plasma samples from 10 rare minnows were pooled as one replicate $(n=6)$. Plasma E2, T and VTG were measured by using enzyme-linked immunosorbent assays (ELISA) kits (Cusabio, Wuhan, Hubei, China) following the manufacturer's recommendations. All samples were analyzed simultaneously to avoid inter-assay variability. Assay sensitivities were $0.025,0.05$ and $50 \mathrm{ng} / \mathrm{ml}$ for E2, T and VTG, respectively, and the intra- and inter-assay coefficients of variation were $<10 \%$.

\subsection{Histological analysis}

Liver and gonad samples were fixed in Bouin's solution for $48 \mathrm{~h}$ and then transferred to $70 \%$ ethanol. After dehydration in a series of ascending concentrations of ethanol (70\%-100\%), these samples were cleared in histoclear and embedded in paraffin. Sections were cut at 3-4 $\mu \mathrm{m}$ and stained with hematoxylin and eosin ( $\mathrm{H}$ and $\mathrm{E}$ ). 
Imaging of sections was carried out using an optical microscope BX53 (Olympus, Tokyo, Japan) and analyzed with an imaging software cellSens Standard (Olympus, Tokyo, Japan). To assess hepatic damage, the number of akaryotes and nucleated cells was counted in both the control group and the DCNP-treated group. Five fields of visions for each section were randomly selected and analyzed. Statistical significance was set at a level of $\mathrm{p}<0.05$ after student's $t$-test $(\mathrm{n}=10)$. To assess gonad damage, the number of perinucleolar oocytes and degenerated oocytes in the histological sections was counted. The frequency of the presence of mature sperm in males was also assessed to determine the percent of spermatogenesis inhibition.

\subsection{Determining gene expression by real-time $P C R$}

Total RNA was extracted from the dissected organs $(n=6$ per treatment) using SV total RNA isolation kits (Promega, Madison, WI, USA). Concentration and quality of RNA was determined spectrophotometrically and confirmed by gel electrophoresis. Real-time PCR was performed in a Fast 7500 real-time quantitative polymerase chain reaction system (Life Technologies, USA) using the Brilliant II SYBR Green QPCR master mix and $300 \mathrm{nM}$ forward/ reverse primer (Table $\mathrm{S} 1$ ). Cycling parameters were as follows: $95^{\circ} \mathrm{C}$ for $8 \mathrm{~min}$; 40 cycles of $95^{\circ} \mathrm{C}$ for $15 \mathrm{~s}, 57^{\circ} \mathrm{C}$ for $30 \mathrm{~s}$ and $72^{\circ} \mathrm{C}$ for $30 \mathrm{~s}$. For each sample, melting curve analysis was performed on the PCR products at the end of each run to ensure that a single product was amplified. To determine the efficiency of the PCR reaction, standard curves and primer efficiencies were determined for target genes and the endogenous control gene $\beta$-actin, with 10 serial dilutions of the cDNA samples. The PCR efficiencies were ranged from $89.1 \%$ to $97.0 \%$ in the present study. The basal mRNA expression for the selected genes was calculated by the $2^{-\Delta \Delta C t}$ method (Schmittgen and Livak, 2008) using $\beta$-actin as the reference gene. The ratios for the treated samples were calculated via comparisons to the expressions in control group.

\subsection{Statistical analysis}

The experimental data were checked for normality and homogeneity of variance using Kolmogorov-Smirnov and Levene's tests, respectively. Differences between the control and exposure group were evaluated by one-way analysis of variance (ANOVA) followed by Dunnett's multiple comparisons test was performed using SPSS 13.0 (SPSS, Chicago, IL, USA) and OriginPro 8.0 (OriginLab, Northampton, MA, USA). P-values less than 0.05 were considered significant. All data were expressed as the mean \pm standard error of the mean (S.E.M.).

\section{Results}

\subsection{Mortality and growth}

In the adult fish experiment, mortality, body length, bodyweight, HSI and GSI were determined in treatment and control groups after DCNP exposure (Table 1). No mortality was observed. Body length, bodyweight, HSI and GSI of the rare minnows in all treatments did not show statistically significant differences compared to the controls.

In the juvenile fish experiment, no mortality was observed. There were no significant differences in body length and bodyweight among those groups (Table 1). However, the GSI was significantly decreased in the 2 and $200 \mu \mathrm{g} / \mathrm{L}$ treatments by $47.39 \%$ and $52.6 \%$ ( $\mathrm{p}<0.05$ ), while no significant change in HSI was observed (Table 1 ).

\subsection{Histopathology}

In the adult fish experiment, the hepatocytes from the controls were compactly arranged and exhibited a normal structure (Fig. 1A). Compared to the control fish, no obvious histological changes were seen in the livers of the rare minnows following exposure to 2 and $20 \mu \mathrm{g} / \mathrm{L} \mathrm{DCNP}$ (data not shown). Disruption of the spatial architecture and cellular vacuolization were observed in the $200 \mu \mathrm{g} / \mathrm{L}$ treatment group. Hypertrophy of the hepatocytes and nuclear pyknosis were also observed in the $200 \mu \mathrm{g} / \mathrm{L}$ treatment group (Fig. 1B).

All testes from controls were at an advanced stage of spermatogenesis, and mature sperm were abundant and represented the predominant germ cells in all fish (Fig. 1C). The histological changes in the testes in all of the male fish after 28-d exposure to 2 or $20 \mu \mathrm{g} / \mathrm{L}$ DCNP were similar to those observed in the control fish (data not shown). However, a lower proportion of mature sperm was observed in the testes in the $200 \mu \mathrm{g} / \mathrm{L}$ treatment group (Fig. 1D). These results indicated that DCNP exposure caused the inhibition of spermatogenesis.

Moreover, control oocytes generally developed into mature oocytes, which were stained red by eosin (Fig. 1E). Histological analysis showed that there was no significant difference in females among 2 and $20 \mu \mathrm{g} / \mathrm{L}$ DCNP treatment groups and control group (data not shown). The number of early-stage follicles in the ovaries was higher in the $200 \mu \mathrm{g} / \mathrm{L}$ treatment group (Fig. 1F). Degenerated oocytes were also found in the $200 \mu \mathrm{g} / \mathrm{L}$ treatment group, and perinucleolar oocytes were predominant in the ovaries (Fig. 1F).

\subsection{Plasma VTG and steroid hormones levels}

In the female fish, a slight decreasing trend of plasma VTG was observed in females in all treatment groups, but it was not statistically significant between treatments and controls. However, in males and juvenile fish, exposure to all test concentrations caused significantly increased plasma VTG levels ( $p<0.05$; Fig. 2A). No significant difference was detected in the estradiol levels in females and juvenile fish after DCNP exposure. However, the measured plasma estradiol levels in males were increased by $173.3 \%$ upon exposure to $200 \mu \mathrm{g} / \mathrm{L}$ DCNP ( $<<0.05$; Fig. 2B). In males, plasma testosterone levels were significantly decreased in the 20 and $200 \mu \mathrm{g} / \mathrm{L}$ DCNP treatments, by $60.19 \%$ and $28.31 \%$, while $42.28 \%$ decrease was also observed in the juvenile fish ( $p<0.05$; Fig. $2 \mathrm{C}$ ). Significant increases in the estradiol/testosterone ratio were clearly evident in 20 and $200 \mu \mathrm{g} / \mathrm{L}$ DCNP treatments in females $(153.41 \%$ and $167.62 \%$ ). Moreover, the estradiol/testosterone ratios were found to be significantly increased in males in all exposure groups (135.70\%, 187.89\% and 354.90\%). In juvenile fish, the estradiol/ testosterone ratio only increased in $200 \mu \mathrm{g} / \mathrm{L}$ DCNP exposure groups by $232.61 \%$ ( $p<0.05$; Fig. 2D).

\subsection{Transcriptional levels of the HPG axis-related genes}

The gene expression levels of luteinizing hormone $\beta(\operatorname{lh} \beta)$ and follicle stimulating hormone $\beta(f \operatorname{sh} \beta)$ in the brain were determined (Fig. 3 and Fig. S1). In the females, $\operatorname{lh} \beta$ was significantly increased in the $20 \mu \mathrm{g} / \mathrm{L}$ treatment group (2.24-fold), while no significant changes in $f \operatorname{sh} \beta$ were observed. In the males, both $\operatorname{lh} \beta$ and $f \operatorname{sh} \beta$ were significantly up-regulated in the 20 and $200 \mu \mathrm{g} / \mathrm{L}$ treatment groups (2.31-, 2.66-fold and 2.44-, 2.10-fold), relative to the control, respectively. In the juvenile fish, $f \operatorname{sh} \beta$ was significantly up-regulated in all treatment groups (2.96-, 4.04-, 2.25-fold).

In the liver, genes related to the HPG axis (er $\alpha, \operatorname{er} \beta, \operatorname{ar}, \operatorname{cyp} 17 \alpha$, cyp $19 \alpha, 3 \beta$-hsd, $17 \beta$-hsd, star and $v$ tg) were investigated (Fig. 3 and Fig. S2). In the females, the transcriptional level of er $\alpha$ was 
Table 1

Growth, gonadosomatic index (GSI) and hepatosomatic index (HSI) of rare minnow at the end of DCNP exposure.

\begin{tabular}{|c|c|c|c|c|c|c|}
\hline \multirow[t]{2}{*}{ Concentration (ng/L) } & \multicolumn{3}{|c|}{ Body length (mm) } & \multicolumn{3}{|c|}{ Body weight(g) } \\
\hline & Females & Males & Juvenile & Females & Males & Juvenile \\
\hline Control & $41.95 \pm 0.49$ & $37.31 \pm 0.46$ & $23.35 \pm 0.32$ & $1.14 \pm 0.06$ & $0.93 \pm 0.06$ & $0.62 \pm 0.08$ \\
\hline 2 & $42.12 \pm 0.66$ & $36.85 \pm 0.38$ & $21.97 \pm 0.22$ & $1.26 \pm 0.10$ & $1.03 \pm 0.08$ & $0.64 \pm 0.07$ \\
\hline 20 & $41.10 \pm 0.57$ & $38.22 \pm 0.51$ & $24.16 \pm 0.21$ & $1.02 \pm 0.13$ & $0.97 \pm 0.06$ & $0.74 \pm 0.09$ \\
\hline 200 & $42.34 \pm 0.74$ & $36.17 \pm 0.52$ & $22.12 \pm 0.28$ & $1.27 \pm 0.17$ & $0.88 \pm 0.10$ & $0.75 \pm 0.04$ \\
\hline \multirow[t]{2}{*}{ Concentration (ng/L) } & \multicolumn{3}{|l|}{ GSI(\%) } & \multicolumn{3}{|l|}{$\mathrm{HSI}(\%)$} \\
\hline & Females & Males & Juvenile & Females & Males & Juvenile \\
\hline Control & $15.43 \pm 0.96$ & $4.44 \pm 0.28$ & $2.87 \pm 0.24$ & $2.06 \pm 0.14$ & $1.91 \pm 0.07$ & $2.88 \pm 0.09$ \\
\hline 2 & $14.83 \pm 1.25$ & $4.15 \pm 0.49$ & $1.51 \pm 0.18^{\star}$ & $2.13 \pm 0.13$ & $1.84 \pm 0.27$ & $3.17 \pm 0.13$ \\
\hline 20 & $13.67 \pm 1.21$ & $3.91 \pm 0.37$ & $2.41 \pm 0.25$ & $2.45 \pm 0.27$ & $1.95 \pm 0.07$ & $3.25 \pm 0.17$ \\
\hline 200 & $14.25 \pm 1.17$ & $4.31 \pm 0.35$ & $1.36 \pm 0.16^{*}$ & $2.09 \pm 0.10$ & $2.13 \pm 0.19$ & $3.38 \pm 0.18$ \\
\hline
\end{tabular}

Data expressed as mean \pm S.E. of each treatment $(n>30)$.

*Statistically significant difference from the control $(\mathrm{p}<0.05)$.
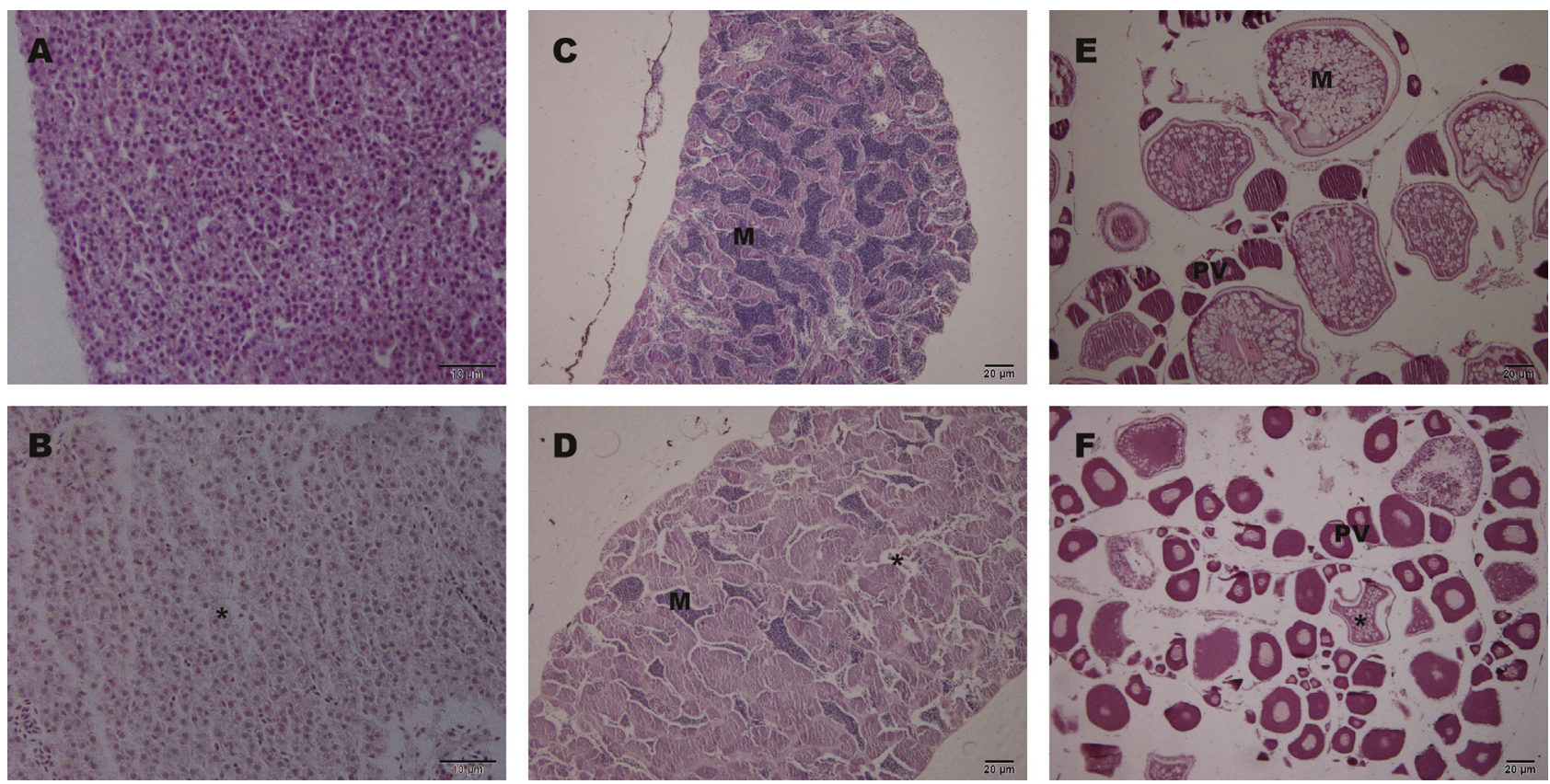

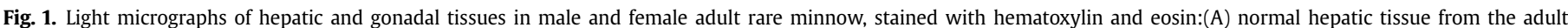

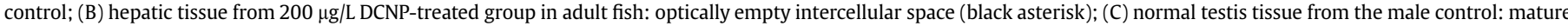

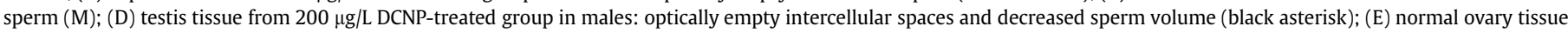

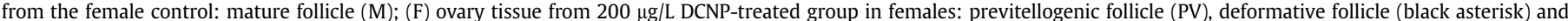
degenerating vitellogenic oocytes (black arrow).

increased in all exposure groups (4.29-, 3.23-, 4.49-fold), while $v$ tg was significantly down-regulated (0.49-, 0.32-, 0.31-fold). In addition, the levels of ar, cyp17 $\alpha$ and star were increased in one or two concentrations. In the males, the levels of ar and cyp17 $\alpha$ were significantly increased in all exposure groups (1.98-, 5.23-, 5.36fold and 2.12-, 2.58-, 3.71-fold), while cyp19 $\alpha$ and star were increased following exposure to $20 \mu \mathrm{g} / \mathrm{L} \mathrm{DCNP}$ (2.06-fold and 3.21fold). In the juvenile fish, the transcriptional level of cyp17 $\alpha$ was significantly increased in all exposure groups (4.50-, 6.19-, 3.08fold). Additionally, no significant changes in $\operatorname{er} \beta, 3 \beta$-hsd, 17 $\beta$-hsd, star and $v t g$ were observed after DCNP exposure.

In the gonads, the transcription levels of $\operatorname{er} \alpha, \operatorname{er} \beta, \operatorname{ar}, \operatorname{cyp} 17 \alpha$, cyp $19 \alpha, 3 \beta$-hsd, $17 \beta$ - $h s d$, star, vtg, lhr and fshr were investigated (Fig. 3 and Fig. S3). In the females, the expression levels of $\operatorname{er} \alpha$, er $\beta$, cyp $17 \alpha$, cyp $19 \alpha$, star and $l h r$ were higher in one or two concentrations ( $\mathrm{p}<0.05)$. In the males, the level of cyp17 $\alpha$ was significantly increased in all exposure groups (2.68-, 4.85-, 5.50-fold), while $17 \beta$ - hsd and $f s h r$ were significantly down-regulated in the $200 \mu \mathrm{g} / \mathrm{L}$ treatment (0.46-fold and 0.32 -fold). In the juvenile fish, er $\alpha$ and cyp $17 \alpha$ mRNA were significantly increased in the 20 and $200 \mu \mathrm{g} / \mathrm{L}$ treatments (7.28-, 3.16-fold and 3.46-, 2.7-fold), while fshr mRNA was significantly down-regulated at the highest concentration (0.45-fold). Meanwhile, no significant differences were observed in the transcriptional levels of cyp $19 \alpha, 3 \beta$-hsd, $17 \beta$-hsd, vtg and lhr.

\section{Discussion}

This study is the first report that demonstrates the endocrine disruption effects of DCNP. After exposure, significant changes were observed in the pathology, plasma VTG level, plasma steroid levels and gene transcription in the HPG axis. Based on these data, DCNP might be considered to have anti-androgenic potential.

In this study, survival of adult and juvenile fish was unaffected by DCNP exposure and did not differ significantly among 

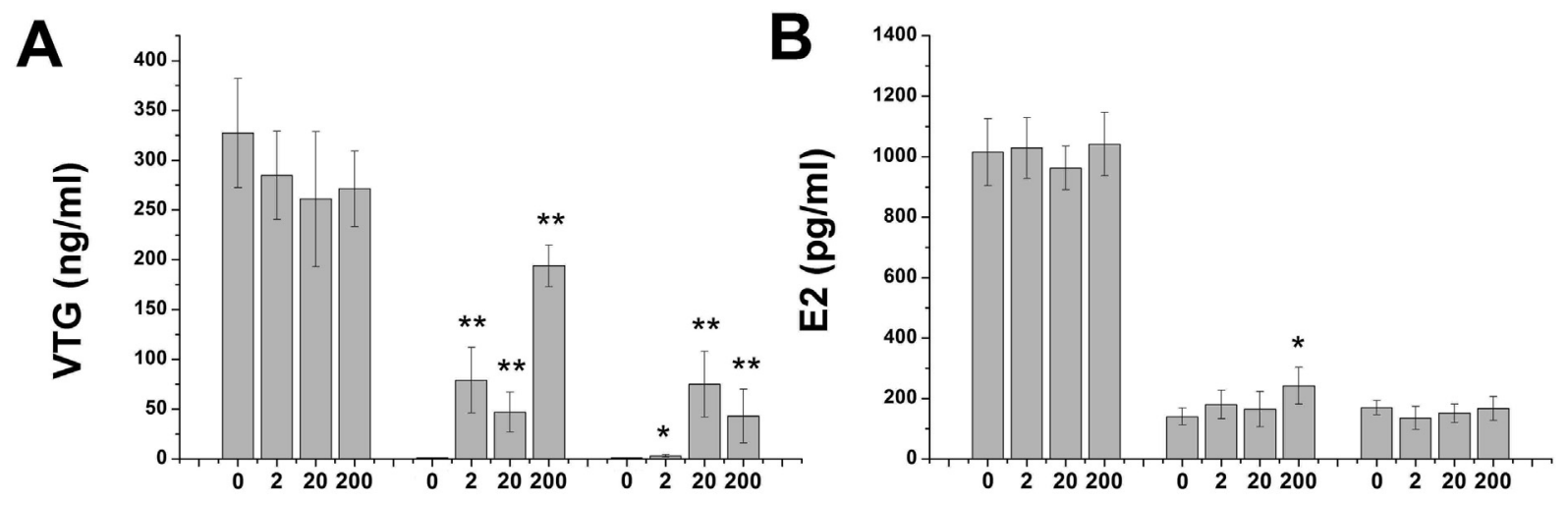

C

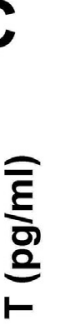

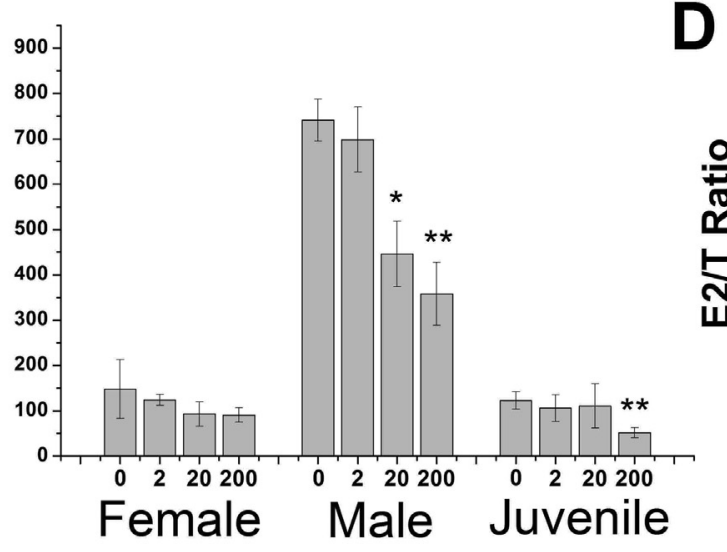
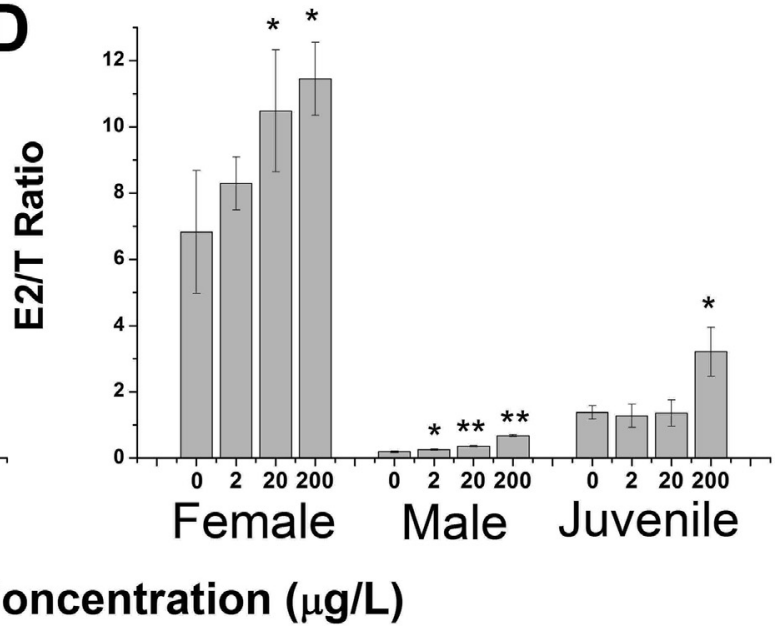

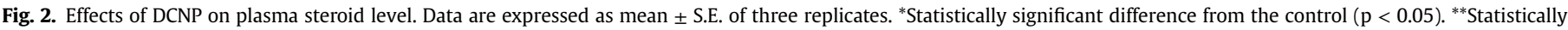
significant difference from the control $(p<0.01)$.

treatments, with nearly $100 \%$ survival overall. Moreover, no differences in either length or bodyweight were observed between treatments and controls at the end of exposure. These results suggested that an environmentally relevant concentration of DCNP was not toxic to growth and development. Nevertheless, cellular vacuolization, hepatocyte hypertrophy and nuclear pyknosis were observed in the liver of the rare minnows, which confirmed the hepatotoxicity induced by DCNP. Similar types of histological damage have been observed in fish exposed to several substituted phenols such as nonylphenol, nitrophenol and DCP (Lam et al., 2013; Zha et al., 2008; Zhang et al., 2008). Additionally, DCNP has been shown to induce oocyte and testis degeneration in this study. Similar morphological changes in the gonads have been observed in rats exposed to 4-nitrophenol or 3-methyl-4-nitrophenol (Yue et al., 2011; Zhang et al., 2013). These pathological changes imply that DCNP may induce hepatic damage and may disrupt reproductive system as an endocrine disruptor.

The plasma VTG level is a frequently used in vivo biomarker for estrogenic activity in oviparous vertebrates and provides an early warning signal of estrogenic contamination in the aquatic environment (Miracle et al., 2006). In female fish, VTG is generally synthesized in the liver under the control of estrogen, is released into the circulation, and is then deposited in developing oocytes (Girish et al., 2014). In male fish, plasma VTG usually cannot be expressed; however, it may be activated by artificial estrogens or estrogen-like EDCs (Henry et al., 2009; Zhong et al., 2014). In this study, the plasma VTG level increased in male fish after DCNP exposure, which confirmed that DCNP was acting as a xenoestrogen. It has been reported that substituted phenols such as 2.4-DCP induce the synthesis of VTG in many fish species (Zhang et al., 2008). However, a slight decrease in female fish at a concentration of $200 \mu \mathrm{g} / \mathrm{L}$ occurred in this study, suggesting weak estrogenic activity of DCNP in female fish. Plasma VTG levels in female and male fish were decreased slightly and increased significantly, respectively, indicating a differential response of gender to DCNP exposure. The mechanism underlying the difference in the response for the plasma VTG levels is not known, but the dual effects on plasma VTG levels were also observed in Japanese medaka when exposed to tamoxifen; plasma VTG decreased in female fish, while it increased in males (Chikae et al., 2004). Baumann (Baumann et al., 2013) reported that 4-tert-pentylphenol, a weak estrogenic active chemical, induced decreased VTG concentrations in a tissue homogenate of female fish and caused strong VTG induction in males. Estradiol stimulates the liver to produce VTG in fish (Girish et al., 2014), which could explain our results in male and juvenile fish. However in the present study, the decreased plasma VTG level was accompanied by an unchanged plasma estradiol level in females. Previous studies have explained that the inhibition of VTG may be mediated by an AHR2-dependent mechanism or caused by liver lesions (Bugel et al., 2013; Garric et al., 1996). Thus, our finding and previous studies suggest that estradiol stimulation was not the only reason for the change of VTG concentration.

In this study, the estradiol concentrations in females and juveniles were unaffected by DCNP exposure. However, concentration of plasma testosterone was reduced both in adult and juvenile rare 


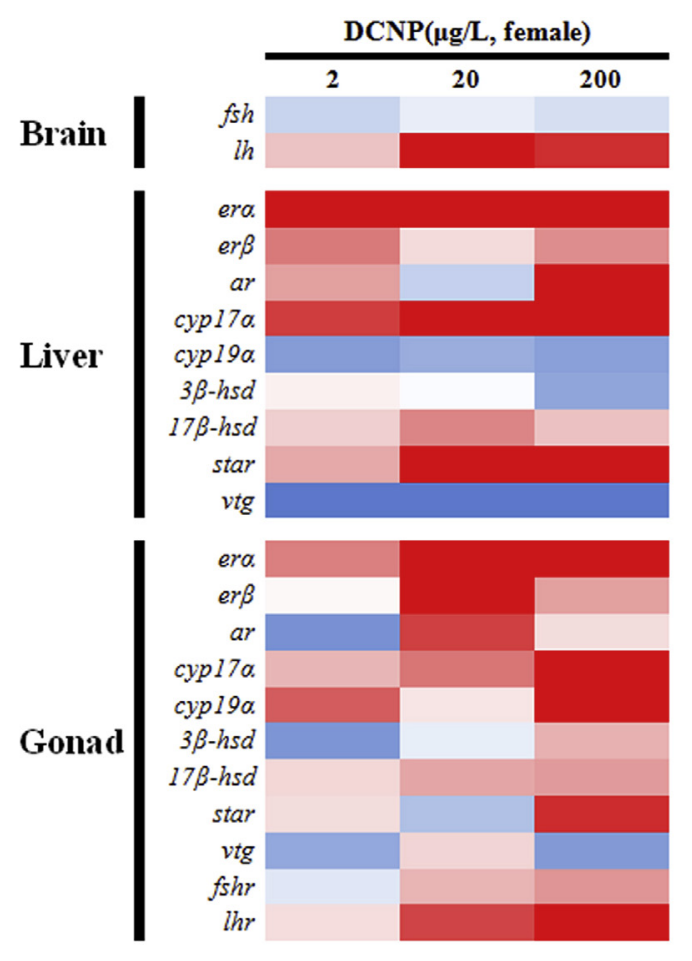

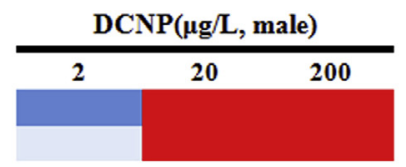
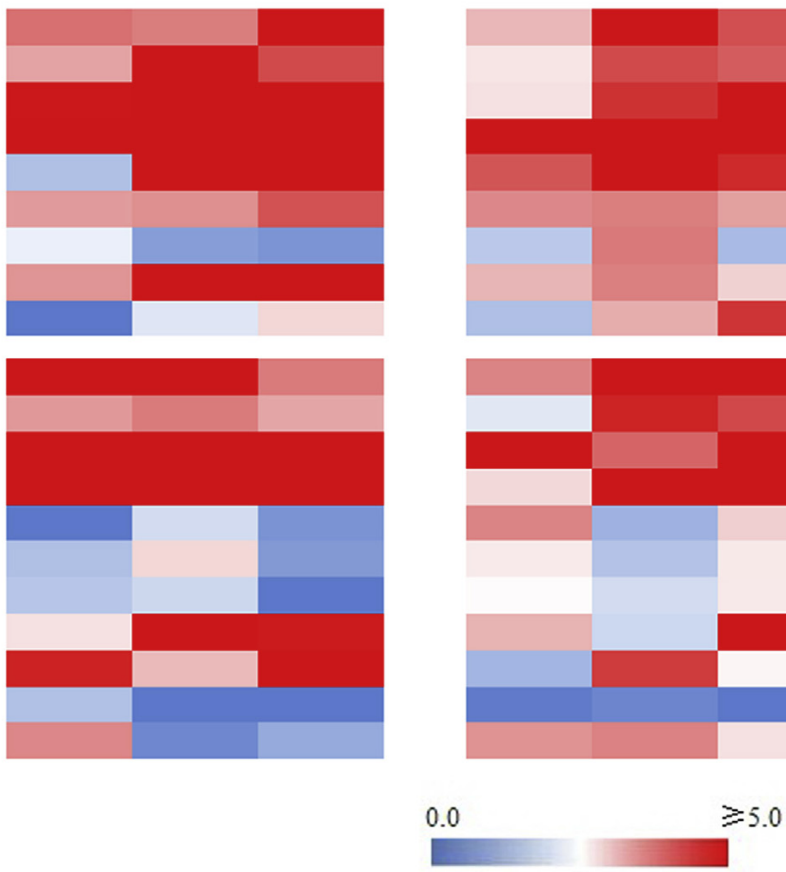

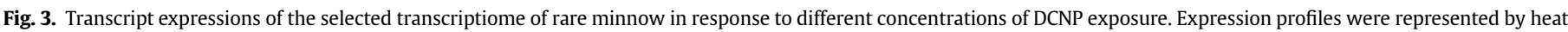
map.

minnows. Regarding the sex steroid levels, the endocrine system in males and juvenile fish was more affected than that in females. Similar observations concerning differential life stage sensitivity have been reported in other studies (Duffy et al., 2014; Liney et al., 2005). Moreover, antiandrogenic effects may be provoked by inhibition of testosterone synthesis. Decreased testosterone levels obtained from fish assays could used to assess anti-androgenic effect within the HPG-axis (Scholz and Mayer, 2008). Antiandrogens, such as vinclozolin and flutamide, have been shown to reduce plasma testosterone concentration in fish (Golshan et al., 2014; Rajakumar et al., 2012). Given the important roles of sex hormones in the gonad development and reproductive system, the antagonistic effect caused by DCNP to endocrine system need to raise concern over its adverse environmental health risks.

The expression of nuclear hormone receptors is regulated by endogenous estrogens/androgen in fish (Bagamasbad and Denver, 2011; Park and Gye, 2014). However, endocrine disrupters, such as nitrophenol, nonylphenol, octylphenol and BPA, also have been shown to induce nuclear receptor transcription (Osachoff et al., 2013; Qiu et al., 2013). Futhermore, these changes of ER/AR mRNA expression could result in reproductive and developmental toxicity (Ma et al., 2012; Nose et al., 2009). In this study, DCNP caused a greater abundance of both er and ar transcripts in the gonads and liver, which implied that DCNP might induce adverse effects by interacting with ER/AR signaling.

A plausible explanation for endocrine disruption by DCNP is steroidogenesis (Hampl et al., 2016), so the effects of DCNP on the expression of mRNA of genes related to steroidogenesis were measured. In this study, the expression of cyp17 $\alpha$ was upregulated in all exposure groups, while cyp $19 \alpha$ and star in the liver of males were increased following exposure to 20 and $200 \mu \mathrm{g} /$
L DCNP. These genes encode enzymes that control the synthesis of estrogen and testosterone and are responsible for the changes in sex hormones. The cyp $17 \alpha$ lies at the crossroads of estrogen and androgen biosynthesis and play a key role in synthesizing testosterone in the testis (Akhtar et al., 2011). From an endocrinological point of view, the changes of CYP17 activity would result in adverse affects on testosterone and estradiol productions (Canton et al., 2006). Thus, this observed increased cyp $17 \alpha$ expression can to some extent be explained by endocrine disrupting effect due to DCNP exposure. The cyp $19 \alpha$ is the terminal enzyme in the steroidogenic pathway, which converts testosterone into estradiol (Martinez-Arguelles et al., 2013). Up-regulation of cyp $19 \alpha$ expression can enhance the efficiency of estradiol synthesis and testosterone consumption, which could explain the reduced production of testosterone in the presence of DCNP (Filby et al., 2007; Liu et al., 2013).

The gonadotropins, luteinizing hormone (LH) and follicle stimulating hormone (FSH) are common regulators of the HPG axis in fish (Nagahama and Yamashita, 2008; Wayne et al., 2007). Evaluation of $f \operatorname{sh} \beta$ and $\operatorname{lh} \beta$ transcription can be used to determine whether environmental chemicals cause disruption of the HPG axis (Castellanos et al., 2013). Except for mRNA expression of $f s h \beta$ in the brains of females, RNA expression of $\operatorname{sh} \beta$ and $\operatorname{lh} \beta$ was up-regulated in rare minnows in the 20 and $200 \mu \mathrm{g} / \mathrm{L}$ treatments. In a previous study, a significant increase in the LH level was accompanied by a decrease in the testosterone level following 3-methyl-4nitrophenol or vinclozolin exposure (Golshan et al., 2014; Li et al., 2006a). Consistent with these results, our results suggested that the up-regulated expression of $f \operatorname{sh} \beta$ and $\ln \beta$ in the brain could be attributed to a pituitary negative feedback mechanism for the regulation of the decreased testosterone level. 


\section{Conclusion}

This is the first study on the anti-androgenic potency of DCNP in Chinese rare minnows, and it has provided insights into the environmental transformation products of phenols that lead to endocrine disruption. In the present study, exposure to DCNP affected the levels of the sex hormones and altered the expression of genes related to nuclear receptors, steroidogenesis and gonadotropin regulation in Chinese rare minnows, thereby resulting in changes in the plasma VTG level. The results of our study highlight the potential anti-androgenic activity of DCNP, which is an environmental by-product of DCP that has formerly received little attention.

\section{Acknowledgements}

This work was supported by the Key Program of the National Natural Science Foundation of China (21437006), the Major International Joint Research Project of the National Natural Science Foundation of China (51420105012), and the Water Pollution Control and Treatment of the National Science and Technology Major Project (2014zx-07204-008-003).

\section{Appendix A. Supplementary data}

Supplementary data related to this article can be found at http:// dx.doi.org/10.1016/j.envpol.2016.06.016.

\section{References}

Akhtar, M., Wright, J.N., Lee-Robichaud, P., 2011. A review of mechanistic studies on aromatase (CYP19) and 17alpha-hydroxylase-17,20-lyase (CYP17). J. Steroid Biochem. Mol. Biol. 125, 2-12.

Bagamasbad, P., Denver, R.J., 2011. Mechanisms and significance of nuclear receptor auto-and cross-regulation. Gen. Comp. Endocrinol. 170, 3-17.

Baumann, L., Holbech, H., Keiter, S., Kinnberg, K.L., Knörr, S., Nagel, T., Braunbeck, T., 2013. The maturity index as a tool to facilitate the interpretation of changes in vitellogenin production and sex ratio in the fish sexual development test. Aquat. Toxicol. 128, 34-42.

Bonefeld-Jorgensen, E.C., Long, M., Hofmeister, M.V., Vinggaard, A.M., 2007. Endocrine-disrupting potential of bisphenol A, bisphenol A dimethacrylate, 4-nnonylphenol, and 4-n-octylphenol in vitro: new data and a brief review. Environ. Health Perspect. 115, 69.

Bugel, S.M., White, L.A., Cooper, K.R., 2013. Inhibition of vitellogenin gene induction by $2,3,7,8$-tetrachlorodibenzo-p-dioxin is mediated by aryl hydrocarbon receptor 2 (AHR2) in zebrafish (Danio rerio). Aquat. Toxicol. 126, 1-8.

Calza, P., Massolino, C., Pelizzetti, E., Minero, C., 2008. Solar driven production of toxic halogenated and nitroaromatic compounds in natural seawater. Sci. Tota Environ. 398, 196-202.

Calza, P., Vione, D., Novelli, A., Pelizzetti, E., Minero, C., 2012. The role of nitrite and nitrate ions as photosensitizers in the phototransformation of phenolic compounds in seawater. Sci. Total Environ. 439, 67-75.

Canton, R.F., Sanderson, J.T., Nijmeijer, S., Bergman, A., Letcher, R.J., van den Berg, M. 2006. In vitro effects of brominated flame retardants and metabolites on CYP17 catalytic activity: a novel mechanism of action. Toxicol. Appl. Pharmacol. 216, $274-281$.

Castellanos, C.G., Sørvik, I.B., Tanum, M.B., Verhaegen, S., Brandt, I., Ropstad, E., 2013. Differential effects of the persistent DDT metabolite methylsulfonyl-DDE in nonstimulated and LH-stimulated neonatal porcine Leydig cells. Toxicol. Appl. Pharmacol. 267, 247-255.

Chikae, M., Ikeda, R., Hasan, Q., Morita, Y., Tamiya, E., 2004. Effects of tamoxifen, $17 \alpha$-ethynylestradiol, flutamide, and methyltestosterone on plasma vitellogenin levels of male and female Japanese medaka (Oryzias latipes). Environ. Toxicol. Pharmacol. 17, 29-33.

Chiron, S., Comoretto, L., Rinaldi, E., Maurino, V., Minero, C., Vione, D., 2009 Pesticide by-products in the Rhône delta (Southern France). The case of 4 chloro-2-methylphenol and of its nitroderivative. Chemosphere 74, 599-604.

Chiron, S., Minero, C., Vione, D., 2006. Photodegradation processes of the antiepileptic drug carbamazepine, relevant to estuarine waters. Environ. Sci. Technol. 40, 5977-5983.

Chiron, S., Minero, C., Vione, D., 2007. Occurrence of 2, 4-dichlorophenol and of 2, 4 dichloro-6-nitrophenol in the Rhône river delta (southern France). Environ. Sci. Technol. 41, 3127-3133.

Crespín, M.A., Gallego, M., Valcárcel, M., González, J.L., 2001. Study of the degradation of the herbicides 2, 4-D and MCPA at different depths in contaminated agricultural soil. Environ. Sci. Technol. 35, 4265-4270.

Czaplicka, M., 2004. Sources and transformations of chlorophenols in the natura environment. Sci. Total Environ. 322, 21-39.

Dehairsl, F. 1991. Spatiotemporal variability of inorganic nitrogen stocks and uptake fluxes in the Scotia-Weddell Confluence area during November and December 1988. Mar. Ecol. Prog. Ser. 77, 7-19.

Deng, J., Liu, C., Yu, L., Zhou, B., 2010. Chronic exposure to environmental levels of tribromophenol impairs zebrafish reproduction. Toxicol. Appl. Pharmacol. 243, $87-95$.

Duffy, T.A., Iwanowicz, L.R., McCormick, S.D., 2014. Comparative responses to endocrine disrupting compounds in early life stages of Atlantic salmon, Salmo salar. Aquat. Toxicol. 152, 1-10.

Dzengel, J., Theurich, J., Bahnemann, D.W., 1999. Formation of nitroaromatic compounds in advanced oxidation processes: photolysis versus photocatalysis. Environ. Sci. Technol. 33, 294-300.

Filby, A.L., Thorpe, K.L., Maack, G., Tyler, C.R., 2007. Gene expression profiles revealing the mechanisms of anti-androgen-and estrogen-induced feminization in fish. Aquat. Toxicol. 81, 219-231.

Gao, J., Liu, L., Liu, X., Zhou, H., Huang, S., Wang, Z., 2008. Levels and spatial distribution of chlorophenols, 2, 4-dichlorophenol, 2, 4, 6-trichlorophenol, and pentachlorophenol in surface water of China. Chemosphere 71, 1181-1187.

Garric, J., Vollat, B., Nguyen, D., Bray, M., Migeon, B., Kosmala, A., 1996. Ecotoxicological and chemical characterization of municipal wastewater treatment plant effluents. Water Sci. Technol. 33, 83-91.

Girish, B., Swetha, C., Reddy, P.S., 2014. Hepatopancreas but not ovary is the site of vitellogenin synthesis in female fresh water crab, Oziothelphusa senex senex. Biochem. Biophys. Res. Commun. 447, 323-327.

Golshan, M., Hatef, A., Zare, A., Socha, M., Milla, S., Gosiewski, G., Fontaine, P., Sokolowska-Mikolajczyk, M., Habibi, H.R., Alavi, S.M., 2014. Alternations in neuroendocrine and endocrine regulation of reproduction in male goldfish (Carassius auratus) following an acute and chronic exposure to vinclozolin, in vivo. Aquat. Toxicol. 155, 73-83.

Gyllenhammar, I., Glynn, A., Darnerud, P.O., Lignell, S., van Delft, R., Aune, M., 2012. 4-Nonylphenol and bisphenol A in Swedish food and exposure in Swedish nursing women. Environ. Int. 43, 21-28.

Hampl, R., Kubátová, J., Stárka, L., 2016. Steroids and endocrine disruptors-History, recent state of art and open questions. J. Steroid Biochem. Mol. Biol. 155, $217-223$.

Heng, Z., Ong, T., Nath, J., 1996a. In vitro studies on the genotoxicity of 2, 4-dichloro6-nitrophenol ammonium (DCNPA) and its major metabolite. Mutat. Res. Genet. Toxicol. 368, 149-155.

Heng, Z.C., Nath, J., Liu, X., Ong, T.m., 1996b. Induction of chromosomal aberrations by 2, 4-dichloro-6-aminophenol in cultured v79 cells. Teratog. Carcinog. Mutagen. 16, 81-87.

Henry, T., McPherson, J., Rogers, E., Heah, T., Hawkins, S., Layton, A., Sayler, G., 2009. Changes in the relative expression pattern of multiple vitellogenin genes in adult male and larval zebrafish exposed to exogenous estrogens. Comp. Biochem. Physiol. Part A Mol. Integr. Physiol. 154, 119-126.

Klinge, C.M., 2000. Estrogen receptor interaction with co-activators and co-repressors. Steroids 65, 227-251.

Kroeger-Koepke, M.B., Koepke, S.R., Hernandez, L., Michejda, C.J., 1992. Activation of a $\beta$-hydroxyalkylnitrosamine to alkylating agents: evidence for the involvement of a sulfotransferase. Cancer Res. 52, 3300-3305.

Lam, S.H., Ung, C.Y., Hlaing, M.M., Hu, J., Li, Z.H., Mathavan, S., Gong, Z., 2013. Molecular insights into 4-nitrophenol-induced hepatotoxicity in zebrafish: transcriptomic, histological and targeted gene expression analyses. Biochim. Biophys. Acta 1830, 4778-4789.

Lei, B., Kang, J., Yu, Y., Zha, J., Li, W., Wang, Z., 2013. $\beta$-estradiol 17-valerate affects embryonic development and sexual differentiation in Japanese medaka (Oryzias latipes). Aquat. Toxicol. 134, 128-134.

Li, C., Taneda, S., Suzuki, A.K., Furuta, C., Watanabe, G., Taya, K., 2006a. Antiandrogenic activity of 3-methyl-4-nitrophenol in diesel exhaust particles. Eur. J. Pharmacol. 543, 194-199.

Li, C., Taneda, S., Suzuki, A.K., Furuta, C., Watanabe, G., Taya, K., 2006b. Estrogenic and anti-androgenic activities of 4-nitrophenol in diesel exhaust particles. Toxicol. Appl. Pharmacol. 217, 1-6.

Li, J., Ma, M., Wang, Z., 2010. In vitro profiling of endocrine disrupting effects of phenols. Toxicol. In Vitro 24, 201-207.

Liang, X., Wang, M., Chen, X., Zha, J., Chen, H., Zhu, L., Wang, Z., 2014. Endocrine disrupting effects of benzotriazole in rare minnow (Gobiocypris rarus) in a sexdependent manner. Chemosphere 112, 154-162.

Liney, K.E., Jobling, S., Shears, J.A., Simpson, P., Tyler, C.R., 2005. Assessing the sensitivity of different life stages for sexual disruption in roach (Rutilus rutilus) exposed to effluents from wastewater treatment works. Environ. Health Perspect. 1299-1307.

Liu, X., Ji, K., Jo, A., Moon, H.-B., Choi, K., 2013. Effects of TDCPP or TPP on gene transcriptions and hormones of HPG axis, and their consequences on reproduction in adult zebrafish (Danio rerio). Aquat. Toxicol. 134, 104-111.

Loiselle, S.A., Bracchini, L., Dattilo, A.M., Ricci, M., Tognazzi, A., Cózar, A., Rossi, C., 2009. The optical characterization of chromophoric dissolved organic matter using wavelength distribution of absorption spectral slopes. Limnol. Oceanogr. 54, 590-597.

Ma, Y., Han, J., Guo, Y., Lam, P.K., Wu, R.S., Giesy, J.P., Zhang, X., Zhou, B., 2012. Disruption of endocrine function in in vitro H295R cell-based and in in vivo assay in zebrafish by 2, 4-dichlorophenol. Aquat. Toxicol. 106, 173-181.

MacAyeal, J.R., 1999. Comprehensive environmental response, compensation, and liability act: the correct paradigm of strict liability and the problem of 
individual causation. UCLA J. Envtl. L. Pol'y 18, 217.

Machado, F., Boule, P., 1995. Photonitration and photonitrosation of phenolic derivatives induced in aqueous solution by excitation of nitrite and nitrate ions. J. Photochem. Photobiol. A Chem. 86, 73-80.

Mack, J., Bolton, J.R., 1999. Photochemistry of nitrite and nitrate in aqueous solution: a review. J. Photochem. Photobiol. A Chem. 128, 1-13.

Maddigapu, P.R., Minella, M., Vione, D., Maurino, V., Minero, C., 2010. Modeling phototransformation reactions in surface water bodies: 2, 4-Dichloro-6Nitrophenol As a case study t. Environ. Sci. Technol. 45, 209-214.

Madronich, S., Flocke, S., 1998. Handbook of Environmental Chemistry. Springer, Heidelberg.

Martinez-Arguelles, D., Campioli, E., Culty, M., Zirkin, B., Papadopoulos, V., 2013. Fetal origin of endocrine dysfunction in the adult: the phthalate model. J. Steroid Biochem. Mol. Biol. 137, 5-17.

Minero, C., Chiron, S., Falletti, G., Maurino, V., Pelizzetti, E., Ajassa, R., Carlotti, M.E. Vione, D., 2007. Photochemincal processes involving nitrite in surface water samples. Aquat. Sci. 69, 71-85.

Miracle, A., Ankley, G., Lattier, D., 2006. Expression of two vitellogenin genes (vg1 and vg3) in fathead minnow (Pimephales promelas) liver in response to exposure to steroidal estrogens and androgens. Ecotoxicol. Environ. Saf. 63, 337-342.

Nagahama, Y., Yamashita, M., 2008. Regulation of oocyte maturation in fish. Dev, Growth Differ. 50, S195-S219.

Nishihara, T., Nishikawa, J.-i., Kanayama, T., Dakeyama, F., Saito, K., Imagawa, M., Takatori, S., Kitagawa, Y., Hori, S., Utsumi, H., 2000. Estrogenic activities of 517 chemicals by yeast two-hybrid assay. J. Health Sci. 46, 282-298.

Nose, T., Tokunaga, T., Shimohigashi, Y., 2009. Exploration of endocrine-disrupting chemicals on estrogen receptor $\alpha$ by the agonist/antagonist differentialdocking screening (AADS) method: 4-(1-Adamantyl) phenol as a potent endocrine disruptor candidate. Toxicol. Lett. 191, 33-39.

Olaniran, A.O., Igbinosa, E.O., 2011. Chlorophenols and other related derivatives of environmental concern: properties, distribution and microbial degradation processes. Chemosphere 83, 1297-1306.

Osachoff, H., Shelley, L., Furtula, V., van Aggelen, G., Kennedy, C., 2013. Induction and recovery of estrogenic effects after short-term $17 \beta$-estradiol exposure in juvenile rainbow trout (Oncorhynchus mykiss). Arch. Environ. Contam. Toxicol. 65, $276-285$.

Palomo, M., Bhandari, A., 2005. Time-dependent sorption-desorption behavior of 2 . 4-dichlorophenol and its polymerization products in surface soils. Environ. Sci. Technol. 39, 2143-2151.

Park, C.J., Gye, M.C., 2014. Sensitization of vitellogenin gene expression by low doses of octylphenol is mediated by estrogen receptor autoregulation in the Bombina orientalis (Boulenger) male liver. Aquat. Toxicol. 156, 191-200.

Qiu, L.L., Wang, X., Zhang, X.H., Zhang, Z., Gu, J., Liu, L., Wang, Y., Wang, X. Wang, S.L., 2013. Decreased androgen receptor expression may contribute to spermatogenesis failure in rats exposed to low concentration of bisphenol A. Toxicol. Lett. 219, 116-124.

Rajakumar, A., Singh, R., Chakrabarty, S., Murugananthkumar, R., Laldinsangi, C. Prathibha, Y., Sudhakumari, C.C., Dutta-Gupta, A., Senthilkumaran, B., 2012. Endosulfan and flutamide impair testicular development in the juvenile Asian catfish, Clarias batrachus. Aquat. Toxicol. 110-111, 123-132.

Schmittgen, T.D., Livak, K.J., 2008. Analyzing real-time PCR data by the comparative CT method. Nat. Protoc. 3, 1101-1108.

Scholz, S., Mayer, I., 2008. Molecular biomarkers of endocrine disruption in small model fish. Mol. Cell Endocrinol. 293, 57-70.
Schulze, T., Weiss, S., Schymanski, E., von der Ohe, P.C., Schmitt-Jansen, M. Altenburger, R., Streck, G., Brack, W., 2010. Identification of a phytotoxic phototransformation product of diclofenac using effect-directed analysis. Environ. Pollut. 158, 1461-1466.

Suzuki, J., Okazaki, H., Nishi, Y., Suzuki, S., 1982. Formation of mutagens by photolysis of aromatic compounds in aqueous nitrate solution. Bull. Environ. Contam. Toxicol. 29, 511-516.

Tognazzi, A., Dattilo, A.M., Bracchini, L., Rossi, C., Vione, D., 2012. Chemical characterisation of a new estuarine pollutant (2, 4-Dichloro-6-Nitrophenol) and assessment of the acute toxicity of its quinoid form for Artemia salina. Int. J. Environ. Anal. Chem. 92, 1679-1688.

Vione, D., Maurino, V., Minero, C., Pelizzetti, E., Harrison, M.A., Olariu, R.-I., Arsene, C., 2006. Photochemical reactions in the tropospheric aqueous phase and on particulate matter. Chem. Soc. Rev. 35, 441-453.

Vione, D., Minero, C., Housari, F., Chiron, S., 2007. Photoinduced transformation processes of 2, 4-dichlorophenol and 2, 6-dichlorophenol on nitrate irradiation. Chemosphere 69, 1548-1554.

Wang, Y., Chen, J., Lin, J., Wang, Z., Bian, H., Cai, X., Hao, C., 2009. Combined experimental and theoretical study on photoinduced toxicity of an anthraquinone dye intermediate to Daphnia magna. Environ. Toxicol. Chem. 28, $846-852$.

Wayne, C.M., Fan, H.-Y., Cheng, X., Richards, J.S., 2007. Follicle-stimulating hormone induces multiple signaling cascades: evidence that activation of Rous sarcoma oncogene, RAS, and the epidermal growth factor receptor are critical for granulosa cell differentiation. Mol. Endocrinol. 21, 1940-1957.

Yuan, L., Lv, B., Zha, J., Wang, Z., Wang, W., Li, W., Zhu, L., 2013. New cytochrome P450 1B1, 1C1, 2Aa, 2Y3, and 2K genes from Chinese rare minnow (Gobiocypris rarus): molecular characterization, basal expression and response of rare minnow CYP1s and CYP2s mRNA exposed to the AHR agonist benzo [a] pyrene. Chemosphere 93, 209-216.

Yue, Z., She, R., Bao, H., Li, W., Wang, D., Zhu, J., Chang, L., Yu, P., 2011. Exposure to 3 methyl-4-nitrophenol affects testicular morphology and induces spermatogenic cell apoptosis in immature male rats. Res. Vet. Sci. 91, 261-268.

Zha, J., Sun, L., Zhou, Y., Spear, P.A., Ma, M., Wang, Z., 2008. Assessment of $17 \alpha-$ ethinylestradiol effects and underlying mechanisms in a continuous, multigeneration exposure of the Chinese rare minnow (Gobiocypris rarus). Toxicol. Appl. Pharmacol. 226, 298-308.

Zha, J., Wang, Z., Wang, N., Ingersoll, C., 2007. Histological alternation and vitellogenin induction in adult rare minnow (Gobiocypris rarus) after exposure to ethynylestradiol and nonylphenol. Chemosphere 66, 488-495.

Zhang, X., Zha, J., Li, W., Yang, L., Wang, Z., 2008. Effects of 2, 4-dichlorophenol on the expression of vitellogenin and estrogen receptor genes and physiology impairments in Chinese rare minnow (Gobiocypris rarus). Environ. Toxicol. 23 694-701.

Zhang, Y., Piao, Y., Li, Y., Song, M., Tang, P., Li, C., 2013. 4-Nitrophenol induces Leydig cells hyperplasia, which may contribute to the differential modulation of the androgen receptor and estrogen receptor- $\alpha$ and- $\beta$ expression in male rat testes. Toxicol. Lett. 223, 228-235.

Zhong, L., Yuan, L., Rao, Y., Li, Z., Zhang, X., Liao, T., Xu, Y., Dai, H., 2014. Distribution of vitellogenin in zebrafish (Danio rerio) tissues for biomarker analysis. Aquat. Toxicol. 149, 1-7.

Zhong, W., Wang, D., Xu, X., 2012. Phenol removal efficiencies of sewage treatment processes and ecological risks associated with phenols in effluents. J. Hazard. Mater. 217, 286-292. 